\title{
A Study on the Smart Tourism Awareness through Bigdata Analysis*
}

\author{
Song-Yi LEE ${ }^{1}$, Hwan-Soo LEE ${ }^{2}$ \\ Received: April 06, 2020. Revised: April 25, 2020. Accepted: May 05, 2020.
}

\begin{abstract}
Purpose: In the 4th industrial revolution, services that incorporate various smart technologies in the tourism sector have begun to gain popularity. Accordingly, academic discussions on smart tourism have also started to become active in various fields. Despite recent research, the definition of smart tourism is still ambiguous, and it is not easy to differentiate its scope or characteristics from traditional tourism concepts. Thus, this study aims to analyze the perception of smart tourism exposed online to identify the current point of smart tourism in Korea and present the research direction for conceptualizing smart tourism suitable for the domestic situation. Research design, data, and methodology: This study analyzes the perception of smart tourism exposed online based on 20,198 news data from portal sites over the past six years. Data on words used with smart tourism were collected from the leading portal sites Naver, Daum, and Google. Text mining techniques were applied to identify the social awareness status of smart tourism. Network analysis was used to visualize the results between words related to smart tourism, and CONCOR analysis was conducted to derive clusters formed by words having similarity. Results: As a result of keyword analysis, the frequency of words related to the development and construction of smart tourism areas was high. The analysis of the centrality of the connection between words showed that the frequency of keywords was similar, and that the words "smartphones" and "China" had relatively high connection centrality. The results of network analysis and CONCOR indicated that words were formed into eight groups including related technologies, promotion, globalization, service introduction, innovation, regional society, activation, and utilization guide. The overall results of data analysis showed that the development of smart tourism cities was a noticeable issue. Conclusions: This study is meaningful in that it clearly reflects the differences in the perception of smart tourism between online and research trends despite various efforts to develop smart tourism in Korea. In addition, this study highlights the need to understand smart tourism concepts and enhance academic discussions. It is expected that such academic discussions will contribute to improving the competitiveness of smart tourism research in Korea.
\end{abstract}

Keywords : Smart tourism, Awareness, Big data, Text-mining, News

JEL Classification Code : L8, Z30, M15

\section{1. 서 론}

* This work was supported by the Ministry of Education of the Republic of Korea and the National Research Foundation of Korea (NRF-2019S1A3A2098438).

1 First Author, Master student, Department of Information Technology and Law, Dankook University, Korea, Email: 94sylee@naver.com

2Corresponding Author, Assistant Professor, Department of Convergence Security, Dankook University, Korea,

Email: hanslee992@gmail.com

(c) Copyright: The Author(s)

This is an Open Access article distributed under the terms of the Creative Commons Attribution Non-Commercial License (http://Creativecommons.org/licenses/by-nc/4.0/) which permits unrestricted noncommercial use, distribution, and reproduction in any medium, provided the original work is properly cited.
4 차 산업혁명 시대에 접어들면서 '스마트'라는 개념은 스마트러닝, 스마트홈, 스마트워크, 스마트카 등과 같이 다양한 산업분야에서 혁신을

그러나 스마트관광은 과잉관광으로 인한 관광지 편중 현상이나 개인정보 침해를 통한 범죄 등 여러 사회적 이슈를 야기하기도 하였다(Pradhan, Oh, \& Lee, 2018). 일례로 스마트관광 서비스를 위해 개인의 동의를 얻지 않은 채 위치정보 서비스를 제공하는 것은 개인의 사생활 침해를 일으킬 수 있는 문제이기 때문이다. 또한, 관광 의미하는 용어로 활용되어 왔다. 최근 관광 분야에서도 스마트 기술이 활용되면서 스마트관광이라는 개념으로 관광서비스의 새로운 변화를 견인하고 있다(Koo, Shin, Kim, Kim, \& Chung, 2013). 스마트관광은 소비자에게 맞춤형 정보를 제공하여 보다 향상된 관광경험을 즐길 수 있도록 하면서 여행객들에게 새로운 관광 문화를 제공하기 시작하였다. 
스마트관광 연구는 정보기술, 경영, 행정, 법률 등 융합적 성격을 가지고 있어 전통적인 관광학의 영역을 넘어 다양한 학문 분야에서 논의되고 있다. 최근의 스마트관광 연구는 국내 연구자들을 중심으로 학문적 정체성 확립과 응용 연구 주제 발굴이 이루어지고 있는데 경희대의 스마트관광 연구소(http://strc.khu.ac.kr/)가 국내 대표적인 스마트관광 연구기관이다. 스마트관광 연구소는 스마트관광 생태계 활성화를 위해 정책적/관리적 시사점을 제공하는 실용적 연구성과를 지속적으로 창출하고 있는 세계적 수준의 연구 집단이다. 특히 스마트관광의 개념을 국내 처음으로 도입하였고, 스마트관광 산업 발전을 위한 융합적 연구 및 정책 수립지원 등 다양한 노력을 추진해 왔다. 그러나 이러한 연구기관의 학술적 노력에도 불구하고 스마트관광 개념 자체가 국내에 소개 된지 얼마 되지 않았기 때문에 학술적 논의의 활성화나 대중의 인식 수준 개선은 여전히 필요한 상황이다. 일례로 '스마트관광'에 대한 개념 정의는 여전히 모호한 것이 현실이다(Koo et al, 2014). 그 범위나 특성을 전통적인 개념(ex e-tounism)과 차별화하는 것도 필요한 과제로 보인다.

이에 본 연구에서는 국내에서 진행된 스마트관광 관련 연구 동향과 온라인 상에서의 뉴스를 중심으로 스마트관광에 대한 담론을 살펴보고 스마트관광 분야 저변 확대를 위한 연구 방향에 대해 논의하고자 한다.

\section{2. 관련 연구}

\section{1. 스마트관광}

관광산업은 국가의 경제 환경에 미치는 영향이 큰 중요한 산업이다 (Pumomo, Rahayu, Riani, Suminah, \& Udin, 2020). 이에 많은 국가들이 정보통신기술과의 융합을 통해 관광산업 진흥을 위한 노력을 추진해 왔다(Lee \& Jing, 2015). 과거에는 주로 정보통신기술이 항공사의 업무시스템에서 주로 활용되어 왔으나 1990 년대부터 본격적으로 관광산업에 정보통신기술이 융합되어 사용되기 시작하였다(Buhalis, 1998). 2000 년대에는 인터넷을 통하여 관광상품을 판매하는 상업적인 웹사이트가 등장하기 시작하면서 e-Tounism 이라는 개념이 등장하였다(Arturo, José, \& Migueal, 2011). 이후 4 차 산업혁명은 관광 분야에도 영향을 미쳐 e-Tounism 을 스마트관광의 개념으로 발전시켰다. 기존의 인터넷만을 활용한 방식으로는 다양해지는 소비자의 욕구를 충족시키기에 한계가 있기 때문이다. 이에 보다 고도화된 정보기술을 결합한 스마트관광이라는 개념이 새롭게 등장하게 되었다. 2010 년대에는 스마트폰의 등장으로 관광객은 본인의 관광지 선택 및 평가 정보를 실시간으로 공유를 하기 시작하면서 스마트관광 개념이 구체화되기 시작하였다(Li \& Lee, 2017; Wang, Park, \& Fesenmaier, 2012).
스마트관광은 관광을 위하여 다양한 기술의 결합을 설명하는 보편적 용어로 활용되고 있다(Gretzel, Sigala, Xiang, \& Koo, 2015). Koo et al. (2014)은 스마트관광을 스마트 정보통신기술을 이용하여 소비자가 장소와 시간에 구애 받지 않고 모든 관광 참여자와 서비스 제공자로부터 최적화된 서비스를 제공받는 관광으로 정의하였다. Gretzel, Sigala, Xiang, and Koo (2015) 기반과 사회적 관계, 수집된 정부의 조직 및 인적 자원을 진보된 기술과 통합함으로써 데이터를 현장의 경험 및 사업적 가치가 있는 것으로 바꾸는 활동으로 보았다. 초기에는 스마트관광을 새롭게 등장하는 정보기술의 결합을 중심으로 설명했다면(Koo et al, 2014), 최근에는 빅데이터를 바탕으로 소비자에게 관광과 관련된 맞춤형 서비스나 정보를 제공하는 개념으로 확장되고 있다(Choi, 2017).

객을 유도하기 위하여 범죄 피해 사실 등은 숨김으로써 소비자의 여행 안전을 위협하는 문제도 발생 가능하다. 이러한 사회적 문제에 대한 논의도 최근 들어 해결해야 할 과제로 논의되고 있는 추세이다.

\section{2. 스마트관광 서비스}

오늘날의 스마트관광 서비스는 빅데이터 분석 및 머신러닝 등 다양한 기술을 활용하여 소비자에게 맞춤형 정보를 제공하고 있다. 정보통신기술은 빠른 속도로 발전하고 있으며 이와 더불어 관광산업과 빠르게 융합되어 새로운 기술을 매번 선보이고 있다. 많은 관광객들은 보다 편리해진 서비스를 통하여 맞춤형 관광서비스인 스마트관광 서비스를 활용하고 있다.

국내 스마트관광 서비스는 대부분 스마트폰을 중심으로 제공되고 있다(Cho, 2019; Choi, 2017). 한국관광공사에서 운영하는 애플리케이션 '대한민국 구석구석'이 대표적인 스마트폰 기반의 스마트관광 서비스라고 할 수 있다. 스마트폰 사용자는 애플리케이션을 통하여 전국의 관광정보 및 다양한 이미지 컨텐츠 등을 제공받는다. 또한, 스마트폰 사용자는 스마트폰의 위치서비스를 통하여 애플리케이션 사용자의 위치를 파악하여 주변의 문화재 정보를 제공받을 수 있다. 최근에는 증강현실 서비스를 활용하여 간접적으로 관광지를 체험할 수 있는 서비스로 발전하고 있다 (Guttentag, 2010).

문화관광과 ICT 기술을 접목시킨 '내손안의 경복궁' 서비스는 미래창조과학부와 문화재청(http://english.cha.go.kr/) 이 공동으로 추진한 사업이다. 2013 년 '내 손안의 덕수궁'이라는 애플리케이션의 시범운영을 통해 확장된 서비스로 애플리케이션 사용자는 스마트폰의 카메라를 문화재에 비치면 증강현실 기술을 통하여 과거 왕좌의 모습을 볼 수 있다. 위치기반 서비스를 통하여 사용자는 현재 위치와 함께 주변 건물에 대한 소개를 받는 등 개인의 취향에 따라 관람 경로를 선택하고 안내를 받을 수 있다. 특히 가상현실 서비스를 적극 활용함으로써 
경복궁의 꽃이 활짝 피어나는 꽃담을 구경하는 등 새로운 콘텐츠를 제공받을 수 있는 특징이 있다.

또한, 한국관광공사 (http//kto.visitkoreaork/k/)는 새로운 일자리 창출을 위하여 SK 플래닛과 공동으로 스마트관광 공모전을 매년 개최하고 있다. 공모전을 통하여 오픈 플랫폼을 활용하여 우수한 애플리케이션 서비스를 발굴 및 창업지원 등 스마트관광생태계 조성에 중심 역할을 하고 있다. ICT 기술과 $\mathrm{K}$ 팝이 접목된 사례 또한 존재한다. 미래창조과학부 (https//mw.msitgo.kr/)와 YG 엔터테인 먼트가 공동으로 개발한 클라이브(Klive)는 고해상도의 홀로그램 영상에 가상현실 및 증강현실을 적용하여 마치 가수가 실제로 공연하고 있는 듯한 생동감과 현실감을 제공한다.

해외에서는 비교적 다양한 스마트관광 서비스를 제공하고 있다. 프랑스 루브르 박물관에서는 '루브르-DNP 박물관 랩(Loume-DNP Museum Lab)'을 설계하여 관광객에게 문화유물을 $3 \mathrm{D}$ 영상 시뮬레이션으로 제공하고 있다. 전용 단말기에 작품을 비추면 관광객은 증강현실 기술을 통하여 만들어진 큐레이터가 나타나 전시 안내를 받을 수 있으며, 훼손되거나 사라진 문화유물을 $3 \mathrm{D}$ 입체영상을 통하여 볼 수 있다(Maehara, Yatsugi, Kim, \& Ushiama, 2012).

영국 런던박물관에서는 첨단 ICT 기술을 접목하여 '스트리트 뮤지엄(Street Museum)'이라는 애플리케이션을 개발하였다. 관광객은 애플리케이션을 통하여 런던의 역사적인 현장을 증강현실을 통하여 체험할 수 있는 관광서비스를 제공받게 된다. 스마트폰의 위치기반 서비스(GPS)를 통하여 관광객 주변의 역사적인 장소의 정보를 제공하고, 사용자는 스마트폰의 카메라를 통하여 인식된 장소와 관련된 런던 박물관이 보유하고 있는 이미지를 3D 영상으로 겹쳐서 보게 된다. 특히 이 기술은 단순히 과거 사진을 보여줌에 그치지 않고 현재의 모습과 과거의 모습을 비교할 수 있기 때문에 사용자는 보다 생생한 체험을 할 수 있다(Economou \& Meintani, 2011). 단순히 건축물이나 문화유산이 보존된 관광지역에 한하여 정보를 제공하는 것이 아니라 관광객이 걷고 있는 길 위에서 관광서비스를 제공함으로써 도시 전체가 하나의 관광지가 되는 것이다.

홍콩에서는 홍콩관광청 웹사이트와 함께 페이스북, 유튜브 등과 같은 소셜미디어 기타 스마트폰 앱을 활용한 전략적 마케팅활동을 추진하고 있다. 홍콩관광청은 홍콩 내 대형 통신사인 PCCW 와 협력하여 홍콩관광청 애플리케이션을 무료로 다운받을 수 있도록 서비스를 제공하는 등 스마트폰을 통하여 다양한 관광서비스를 제공하고 있다(Mak, Lumbers, Eves, \& Chang, 2013).

\section{3. 스마트관광 연구 동향}

관광분야에서도 새로운 기술들이 활용되면서 스마트관광이란 용어가 등장하게 되었고 관련 학술적 논의들을 이끄는 계기가 되었다(Huang,
Goo, Nam, \& Yoo, 2017). 국외 연구 동향을 살펴보면 스마트관광 연구가 아직은 초기인 관계로 스마트관광의 개념과 특성을 정의하고자 하는 연구가 주를 이루고 있다(Wang et al, 2012; Jovici, 2019). 최근 들어 스마트관광 활용 사례가 증가하면서 실증 연구들이 증가하고 있는 추세로 문화유산에 스마트관광 서비스를 활용한 사례(Lopes, Malik, Kumpoh, Keasbery, Hong, Lee, \& Lu, 2019), 모바일을 통한 스마트관광 홍보(Tan, Lee, Lin, \& Ooi, 2017) 등 다양한 응용 연구들이 진행되고 있다. 이러한 논의를 통해 관광경험에서 스마트 기술의 역할에 대한 이해를 높이기 위한 다양한 학술적 논의들이 이루어지고 있다. 그러나 스마트관광 관련 연구가 10 여년 정도의 비교적 짧은 기간 동안 수행되어오면서 'e-관광(e-tounism)', '가상관광 (Virtual tounism)'등 유사한 용어로 파편화되어 연구가 이루어지고 있는 경향이 있다. 그 결과 스마트관광의 개념과 범위를 명확하게 제시하기 어려운 상황이다.

국내의 경우에도 스마트관광 연구가 시작 된지 5 년여 밖에 되지 않았고, 관광, 경영, 호텔/외식산업 등 다양한 학문 분야에서 연구가 이루어지면서 유사한 문제를 내포하고 있다. 스마트관광 분야의 학문적 정체성을 확립하기 위해서는 이러한 문제에 대해 국내에서도 보다 많은 학술적 논의가 이루어져야 스마트관광 연구 활성화 및 경쟁력 확보에 기여할 수 있다. 실제 국내에서 이루어진 스마트관광 연구 동향을 살펴보기 위해 한국학술지인용색인 사이트 (mwn.kcigo.kr)를 확인하였다. '키워드별 연구 동향' 서비스를 활용하여 '스마트관광스마트 관광 포함'을 검색한 국내 논문 게재 현황을 살펴보면 Table 1 과 같다.

Table 1: Topic by year

\begin{tabular}{|c|c|c|}
\hline Year & Number of paper & Main Topics \\
\hline 2014 & 5 & Ecosystem of Smart Tourism \\
\hline 2015 & 5 & Development of Smart Tourism \\
\hline 2016 & 1 & $\begin{array}{c}\text { Smart Tourism and Social } \\
\text { Media }\end{array}$ \\
\hline 2017 & 4 & Influence of Smart Tourism \\
\hline 2018 & 5 & Promotion of Smart Tourism \\
\hline 2019 & 5 & $\begin{array}{c}\text { Smart Tourism and Technology } \\
\text { Convergence }\end{array}$ \\
\hline
\end{tabular}

2014 년부터 2019 년 동안 $\mathrm{Ka}$ 에 등재된 스마트관광 (스마트 관광) 논문은 25 건으로 2016 년 감소했다가 다시 증가 추세에 있다. 대부분 관광학, 호텔/외식산업을 중심으로 연구가 이루어졌으며 최근 경영정보학, 정보기술, 소프트웨어 관련 분야에서 연구가 활성화되고 있는 상황이다. 관광학 분야에서는 주로 스마트관광의 사례를 중심으로 스마트관광 만족도의 결정요인을 파악하기 위한 연구가 이루어졌다. 4 차 산업혁명시대에 접어들면서 새로운 형태의 스마트관광 생태계가 형성되면서 경영학적인 논의가 이루어지고 있고, 관광의 디지털 
트랜스포메이션 관점에서 다양한 시사점을 제시하고 있다 (Yoo, Kwon, $\mathrm{Na}$ \& Chang, 2017). 호텔 및 외식산업 분야에서는 스마트관광 서비스를 이용한 관광객의 관광 경험을 바탕으로 한 관광객의 욕구와 특성 차이 등에 대한 분석이 이루어지고 있다. 기타 과학기술학 분야에서는 스마트관광의 활성화를 위한 지원 서비스 플랫폼 등에 대한 연구가 진행되고 있다.

다양한 분야에서 점차적으로 스마트관광에 대한 논의가 증가되고는 있으나 여전히 스마트 관광을 바라보는 시각은 다양하다. 관광학 분야에서는 관광과 정보통신기술의 결합으로 정의하고 있고 $\left(\mathrm{Li}_{1} \mathrm{Hu}\right.$ Huang, \& Duan, 2017), 경영학분야에서는 관광의 디지털화라는 보다 거시적인 관점에서 정의한다. 호텔 및 외식산업 분야에서는 여행자 중심의 맞춤형 서비스 관점에서 스마트 관광을 주목하고 있다(Koo, Shin, Grezel, Hunter, \& Chung, 2016). 정보시스템 분야에서는 관광서비스와 $\Pi$ 기술의 단순 결합이 아닌 융합이라는 관점에서 접근한다(Del Vecchio, Mele, Ndou, \& Secundo, 2018).

위와 같이 국내 대부분의 연구들에서 관광과 $\Pi$ 기술의 결합 또는 융합으로만 스마트관광 개념으로 정의하고 있어서 최근의 스마트관광 동향이나 미래연구 방향에 대해 제시하는데 다소 한계가 있다. 더욱이 스마트관광에 대한 개념의 모호성으로 개념의 확산을 위한 노력 또한 부족한 실정이다. 이에 본 연구에서는 국내 스마트관광에 대한 인식을 파악함으로써 오늘날에 적합한 스마트관광 개념의 재정의 필요성을 제시하고자 한다.

\section{3. 연구방법}

\section{1. 연구 범위}

본 연구의 목적은 국내 스마트관광에 대한 현황과 인식을 살펴봄으로써 스마트관광 개념의 학술적 재정의 및 응용연구 확장의 필요성을 확인하는데 있다. 온라인상의 뉴스 빅데이터를 중심으로 스마트관광과 관련된 단어를 사회연결망 분석 기법을 활용하여 온라인 상의 스마트관광 인식 현황에 대해 살펴본다. 오늘날 사회가 주목하고 있는 스마트관광 이슈를 파악함으로써 기존의 스마트관광 개념과 실제 스마트관광에 대한 인식의 차이를 확인하여 향후 스마트관광 연구 방향을 제시하는데 연구의 의의가 있다.

\section{2. 측정 도구}

온라인상의 뉴스 빅데이터를 중심으로 스마트관광과 관련 있는 단어를 추출하여 사회연결망 분석(Social Network Analysis) 기법을 통해
실증 분석을 진행하였다. 사회연결망 분석은 온라인 빅데이터에서 수집된 텍스트로부터 의미 연결망을 추출하여 단어 간 의미구조를 파악하는 분석기법이다(Scott, Baggio, \& Cooper, 2008). 대표적 포털사이트인 네이버(Naver), 다음(Daum), 구글(Google)에서 "스마트관광"과 함께 사용되는 단어들을 수집하여 텍스트마이닝을 수행하였다. 데이터 수집 도구로는 텍스톰(Textom)의 데이터 수집 서비스를 이용하였으며, 분석 채널은 뉴스로 한정하였다. 텍스톰 (httpo//mwntextom.co.kr)은 온라인 데이터 크롤링을 대행해주는 업체로 연구자들에게 온라인 빅데이터 분석을 도와주는 서비스이다. 자료검색을 위한 키워드는 '스마트관광과 '스마트 관광'을 함께 사용하였다. 자료의 분석기간은 6년으로 2014 년 1월 1 일부터 2019 년 12 월 31 일까지 연구대상 기간으로 한정하였다. 수집된 데이터는 총 20,198 건의 문서 데이터가 수집되었다. 분석데이터 정보는 아래의 Table 2 와 같다. 네트워크 구조 분석 시 노드의 수가 많으면 시각화 표현에 어려움이 있으므로, 상위 100 개의 키워드로 한정하였다.

Table 2: Research Data

\begin{tabular}{|c|c|}
\hline Category & Content \\
\hline Channel & $\begin{array}{c}\text { Naver(news) } 10,940 \text { counts, } \\
\text { Daum(news) } 8,508 \text { counts, } \\
\text { Google(news) } 750 \text { counts }\end{array}$ \\
\hline Period & $\begin{array}{c}\text { January } 1,2014 \\
\sim \text { December 31, 2019 }\end{array}$ \\
\hline Tool & Textom, Ucinet 6.645, NetDraw \\
\hline Key word & Smart tourism, Smart-tourism \\
\hline
\end{tabular}

\section{3. 측정 방법}

본 연구는 '스마트관광'을 중심으로 사회적 인식 현황을 파악하기 위하여 텍스트 마이닝 기법을 적용하였다. 수집된 데이터에서 오후, 한편, 적극, 대표, 사장, 최고, 이번 등 관련성이 적은 단어들과 모바, 와이파, 인프 등 불완전한 단어를 제거하였다. 또한 의, 을, 를, 에서 등 조사나 문장부호 등을 정제하여 상위 100 개의 단어들로 선정하였다. 소셜 네트워크 상에서 내제되어 있는 스마트관광에 대한 관계 및 인식변화를 파악하기 위하여 Ucinet6.645를 통해 단어들 간의 연결 구조 및 연결 중심성을 수행하였다. 연결 중심성 분석을 통하여 특정한 주제가 배치된 방법을 구조적으로 파악할 수 있었다. Netdraw 를 활용하여 스마트관광과 관련된 단어들 사이의 네트워크를 시각화하였으며, 유사점을 가진 단어들끼리 분리하기 위하여 CONCOR 분석을 실시하였다. 


\section{4. 분석결과}

\section{1. 키워드 분석결과}

2014년 1월 1일부터 2019년 12월 31일(총 6년)동안 스마트관광 키워드를 중심으로 네이버(Naver), 다음(Daum), 구글(Google)의 뉴스를 통하여 추출된 단어의 수는 총 20,198개였다. 2014년 1월 1일부터 2019년 12월 31일(총 6년)까지의 스마트관광 단어를 포함하는 문장의 텍스트 마이닝 수행 결과 상위 100 개의 관련 키워드를 추출하였고, 그 중 상위 50 개 단어를 나열하면 Table 3 과 같다.

Table 3: Keyworkd Frequency

\begin{tabular}{|c|c|c|c|}
\hline Word & Frequency & Word & Frequency \\
\hline Build & 1966 & Smart city & 596 \\
\hline Service & 1779 & Reporter & 595 \\
\hline Development & 1482 & Utilization & 578 \\
\hline Tourism & 1446 & Foreigner & 576 \\
\hline Jeju & 1410 & Conclusion & 572 \\
\hline Provision & 1325 & Seoul & 547 \\
\hline $\begin{array}{c}\text { Korea Tourism } \\
\text { Organization }\end{array}$ & 1304 & Culture & 547 \\
\hline Application & 1275 & Installation & 541 \\
\hline Smart & 1126 & Subject & 537 \\
\hline Business & 1086 & Region & 530 \\
\hline Use & 1054 & Plan & 523 \\
\hline Tourist & 1039 & Technology & 518 \\
\hline Construction & 971 & Support & 515 \\
\hline Implementation & 924 & Free & 506 \\
\hline City & 916 & Tourism & 494 \\
\hline Hosting & 852 & Wi-Fi & 460 \\
\hline Foundation & 816 & Promotion & 458 \\
\hline Contest & 739 & Big data & 436 \\
\hline Smartphone & 719 & Release & 431 \\
\hline Information & 645 & Platform & 429 \\
\hline Tourist spot & 639 & Busan & 424 \\
\hline Operation & 631 & Field & 422 \\
\hline Mobile & 630 & Korea & 421 \\
\hline Smart tourism & 629 & Content & 417 \\
\hline Travel & 622 & Industry & 406 \\
\hline
\end{tabular}

키워드 빈도 결과에 따르면 주로 스마트관광지 개발 및 구축과 관련된 이슈들의 노출 빈도가 높았다. 그리고 관광공사와 제주시를 중심으로 스마트관광이 활성화되어 온 것을 확인할 수 있다.

Table 4: Keyword Centrality

\begin{tabular}{|c|c|c|c|}
\hline Word & Centrality & Word & Centrality \\
\hline Build & 0.038564 & Smart tourism & 0.015073 \\
\hline Service & 0.034031 & Foundation & 0.014965 \\
\hline Tourism & 0.02993 & Installation & 0.014893 \\
\hline Development & 0.029822 & Travel & 0.014641 \\
\hline Jeju & 0.029103 & Subject & 0.014497 \\
\hline Provision & 0.028455 & Plan & 0.01421 \\
\hline Construction & 0.026944 & Smart city & 0.014174 \\
\hline Smart & 0.026477 & Mobile & 0.01313 \\
\hline Application & 0.026045 & Domestic & 0.013058 \\
\hline Reporter & 0.024426 & Busan & 0.012951 \\
\hline Business & 0.023995 & Tourist spot & 0.012195 \\
\hline City & 0.023707 & Release & 0.011943 \\
\hline Implementation & 0.022987 & China & 0.011727 \\
\hline Use & 0.022699 & Korea & 0.011332 \\
\hline Smartphone & 0.022196 & Progress & 0.011296 \\
\hline $\begin{array}{l}\text { Korea Tourism } \\
\text { Organization }\end{array}$ & 0.021728 & Field & 0.011224 \\
\hline Tourist & 0.020973 & Industry & 0.011188 \\
\hline Hosting & 0.017843 & Foreigner & 0.011152 \\
\hline Operation & 0.016692 & Culture & 0.010612 \\
\hline Region & 0.016368 & $\begin{array}{c}\text { Tourism } \\
\text { organization }\end{array}$ & 0.010396 \\
\hline Information & 0.016332 & Expansion & 0.010145 \\
\hline Seoul & 0.015864 & Schedule & 0.010109 \\
\hline Support & 0.015721 & Town & 0.009965 \\
\hline Utilization & 0.015685 & Technology & 0.009749 \\
\hline Promotion & 0.015217 & Future & 0.009677 \\
\hline
\end{tabular}

스마트관광에 대한 연결 중심성 분석결과 중 상위 50 개의 순위는 Table 4와 같다. 연결 중심성 분석결과는 키워드 빈도 와 유사하나 스마트폰과 중국의 연결 중심성이 높은 것은 스 
마트폰 중심의 스마트관광 서비스 활성화와 중국의 최근 스 마트관광 관련 기술의 급격한 성장이 영향을 미친 것으로 보 인다.

\section{2. 네트워크 시각화 분석결과}

네트워크 간의 연결 관계와 패턴을 시각화 및 군집화하 기 위하여 CONCOR 분석을 실시하였다. 상위 100 개의 주요 단어빈도를 활용하여 CONCOR분석을 실시한 결과는 Fig. 1과 같다. 스마트관광과 관련된 키워드는 (1) 스마트시티, 빅데이 터, 관광산업, 기술, 콘텐츠 등 스마트관광의 기술 관련 용어, (2) 온라인, 스마트폰, 체험, 무료 등 스마트관광의 온라인 홍 보 관련 용어, (3) 협력, 세계, 인프라 등 스마트관광의 국제화 와 관련된 용어, (4) 국내, 앱, 시작, 선정 등 스마트관광 서비 스의 초기 도입단계와 관련된 용어, (5) 관광공사, 공동, 창출, 개발 등 스마트관광 산업의 혁신과 관련된 용어, (6) 군, 강원 도, 관광객, 관광지 등 지역사회의 스마트관광 활용과 관련된
용어, (7) 부산, 전국, 관계자, 도입 등 스마트관광의 활성화와 관련된 용어, (8) 외국인관광객, 문화체육관광부, 스마트헬프 등 스마트관광 서비스 활용 가이드와 관련된 용어 등 총 8 개 의 그룹이 형성되었다.

\section{5. 논의 및 결론}

\section{1. 연구 시사점}

본 연구는 빅데이터 분석을 통하여 스마트관광의 사회적 인식 현황에 대하여 살펴보고, 이를 바탕으로 스마트관광 분 야 향후 연구 방향을 논의하고자 하였다. 분석결과에 따르면 '구축', '서비스', '개발' 등의 단어들이 상대적으로 많이 추출된 것을 확인할 수 있었다. 즉, 국내의 스마트관광 산업은 아직 진입 초기 단계임을 확인할 수 있는 결과이다(Choi, 2017).

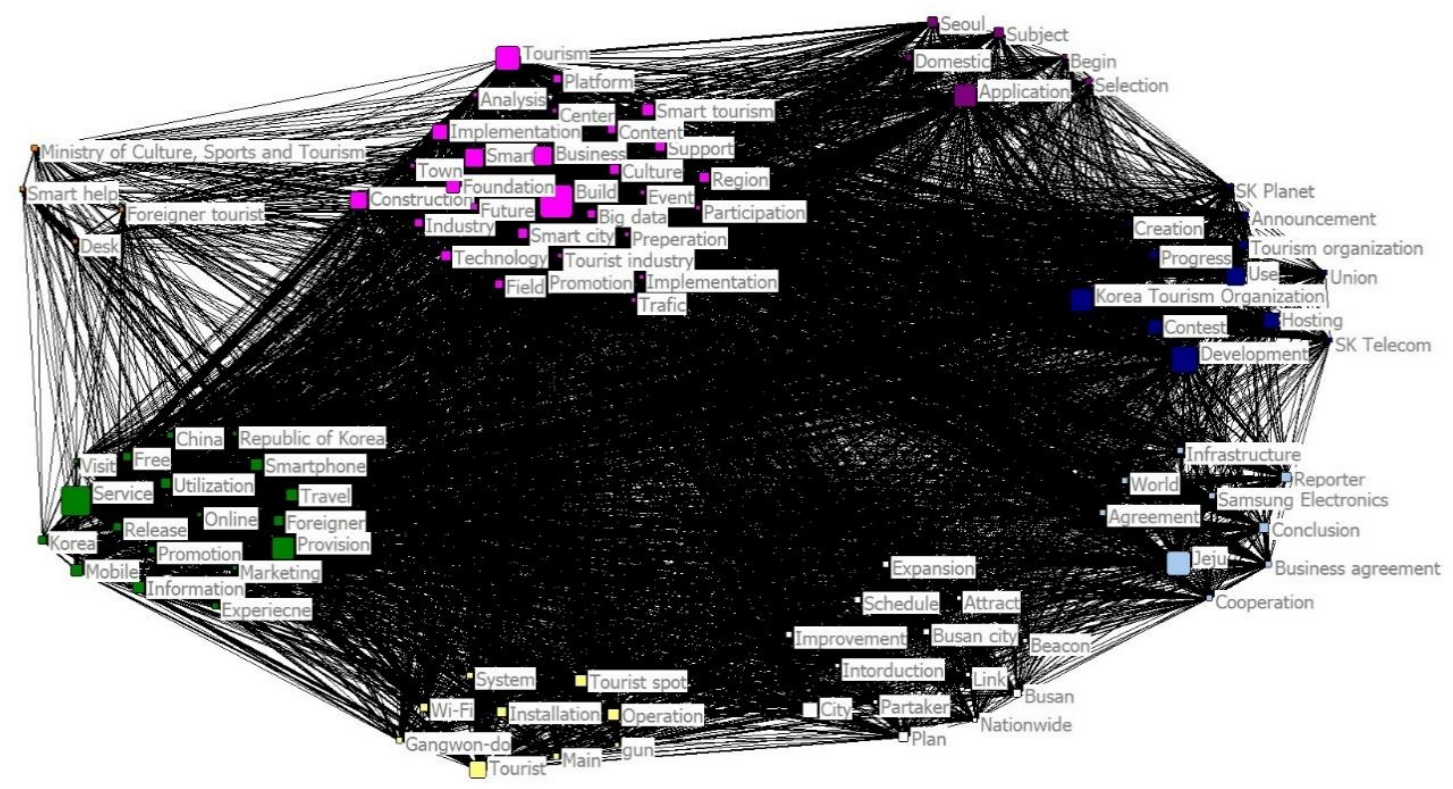

스마트관광 관련 키워드에 대한 CONCOR분석을 실시한 결과, 스마트관광은 빅데이터를 바탕으로 다양한 관광서비스 제공을 기술 및 4차 산업 발전에 따른 기술 환경 변화와 함 께 관광산업도 디지털 중심의 환경으로 변화하고 있음을 보 여주고 있다. 이는 스마트기기 및 소셜미디어의 급성장과 영 향력의 확산을 나타내며 관광객의 다양해진 관광 욕구를 보
여주고 있는 것으로 해석할 수 있다. 이와 함께 스마트관광의 글로벌화를 위하여 다양한 협력에 관한 키워드가 군집화를 보여주고 있는 것을 볼 때 글로벌 관광객 유치를 위한 접근 또한 필요함을 알 수 있다. 우리나라는 국내 외국인 관광객이 급감하면서 이에 대한 대응방안으로 '개별 관광객 맞춤형 스 마트관광 서비스'를 구축하기 시작했고, 중국과 스마트관광 
협력을 맺음으로써 스마트관광의 국제화에 노력해 왔다. 그러 나 최근 중국 스마트관광산업의 급격한 성장은 우리나라 고 유의 스마트관광 콘텐츠 개발 필요성을 보여준다.

또한, 정부에서는 지역 활성화를 위하여 다양한 애플리케 이션 개발에 힘 써온 것을 분석결과를 통해 알 수 있다. 그러 나 스마트관광 서비스 제공을 위한

다양한 애플리케이션을 개발함에도 불구하고 주로 스마트폰 을 이용하여 정보를 제공할 뿐만 아니라 애플리케이션을 이 용한 획일화된 콘텐츠를 제공하고 있음을 확인할 수 있다. 연 령별 스마트폰 소유자의 애플리케이션 활용 빈도 수치가 20 30대에서 가장 높게 나타나는데, 이는 스마트관광 서비스 이용객의 대상이 특정 세대에 편중될 수 있다는 한계를 보여 준다. 또한, 스마트관광연구소(http://strc.khu.ac.kr/)의 분석에 따르면 지자체에서 개발한 30 개의 관광애플리케이션이 제공 하는 서비스는 주로 관광지, 문화유산, 축제 또는 음식이나 교통 등으로 거의 비슷할 뿐만 아니라, 지자체의 $70 \%$ 이상이 애플리케이션의 정보를 1 년 동안 업데이트를 하지 않는 것으 로 나타났다. 이는 향후 스마트관광의 지속성 향상을 위한 지 자체의 전략 수립과 정부의 지원 방안 마련이 필요함을 보여 준다고 하겠다.

스마트관광의 활성화를 위하여 서비스를 이용하는 대상 확대의 필요성 또한 논의되고 있다. 이를 위해서는 다양한 연 령층을 대상으로 흥미를 유발할 수 있는 차별화된 관광콘텐 츠를 개발하고 콘텐츠를 전달하는 다양한 방식이 개발될 필 요가 있다. 분석 결과와 같이 국내 스마트관광 관련 동향은 정부 위주의 스마트관광 활성화를 위한 정책에 한정적임을 볼 수 있다. 이는 국내 스마트관광은 아직 초기의 도입단계이 며 관광객의 스마트관광에 대한 이해 및 서비스 이용에 한계 가 있음을 보여준다.

\section{2. 연구 의의}

본 연구의 학술적 의의는 스마트관광에 대한 포괄적인 문헌연구 및 빅데이터를 바탕으로 한 실증 분석을 수행하여 스마트관광 연구의 활성화 필요성을 논의하였다는데 있다. 문 헌연구에 따르면 스마트관광 개념은 여전히 학술적인 합의가 부족하며 관련 연구주제 또한 제한적으로 논의되고 있다는 것을 확인하였다. 스마트관광에 대한 활발한 연구를 통해 개 념의 체계화 및 다양한 현상을 설명할 수 있는 이론 개발이 필요함을 연구결과는 보여준다. 둘째로, 국내 스마트관광에 대한 온라인 상의 인식을 분석함으로써 스마트관광 사회인식 과 연구 동향의 차이를 확인함과 동시에 향후 연구 방향을
제시한다는 점에서도 의의가 있다. 본 연구의 실무적인 시사 점으로는 온라인에서 공유되고 있는 스마트관광 뉴스정보를 통해서 스마트관광 정책 흐름에 대한 이해와 향후 정책 개발 에 참조할 수 있다는 점에서 의미가 있다.

\section{3. 결론 및 향후 연구방향}

본 연구를 통해 스마트관광 관련 단어의 빈도 및 단어간 연결 중심성을 파악할 수 있었으며, CONCOR분석을 통하여 높은 순위의 단어들과 단어별 군집을 추출할 수 있었다. 추출 된 단어 군집들은 스마트관광 개념에 대한 확산이 더딜 뿐만 아니라 관심 주제에 있어서도 학계와 대중의 인식 차이가 있 음을 보여준다. 따라서 국내의 스마트관광의 현시점에 대해 보다 객관적인 시각에서 살펴보고 활발한 학술적 논의를 통 해 스마트관광 연구분야를 선도하기 위한 노력을 지속해야 할 것이다. 그러나 뉴스 데이터만으로 연구 결과를 일반화하 기에 제한적이라는 점에서 연구의 한계가 있다. 뉴스의 경우 일반인들의 담론이라기 보다는 온라인 매체가 대중에게 전달 하는 일방적 정보이기 때문에 스마트 관광에 대한 보편적 인 식을 확인하기에는 부족함이 있다. 향후 연구에서는 기사의 댓글이나 일반 게시글 등을 포함하여 데이터 분석 범위를 넓 히거나 분석 키워드를 다양화한다면 보다 의미 있는 연구가 될 것으로 기대한다.

\section{References}

Arturo, M. R., José, M. P., \& Migueal, A. G. C. (2011). Otium: A web based planner for tourism and leisure. Expert Systems with Applications, 38(8), 10085-10093.

Buhalis, D. (1988). Strategic use of information technologies in the tourism industry. Tourism Management, 19(15), 409-121.

Cho, S. H. (2019). The effect of mobile tourism app characteristics on perceived value, satisfaction and behavioral intention. International Journal of Industrial Distribution \& Business, $10(9), 45-52$.

Choi, E. H. (2017). Case Study and Implications of Smart Tourism in Korea. KIET Industrial Economic Review, 228, 49-57.

Del Vecchio, P., Mele, G., Ndou, V., \& Secundo, G. (2018). Creating value from social big data: Implications for smart tourism destinations. Information Processing \& Management, 54(5), 847-860.

Economou, M., \& MEintani, E. (2011). Promising Beginning? Evaluating Museum Mobile Phone Apps. Paper presented at Rethinking Technology in Museums 2011.

Gretzel, U., Sigala, M., Xiang, Z., \& Koo, C. (2015). Smart tourism: Foundations and developments. Electronic Markets, 25(3), 179-188.

Guttentag, D. A. (2010). Virtual reality: Applications and implications for tourism. Tourism Management, 31(5), 637- 
651.

Huang, C. D., Goo, J., Nam, K., \& Yoo, C. W. (2017). Smart tourism technologies in travel planning: The role of exploration and exploitation. Information \& Management, 54(6), 757-770.

Jovicic, D. Z. (2019). From the traditional understanding of tourism destination to the smart tourism destination. Current Issues in Tourism, 22(3), 276-282.

Koo, C. M., Baron, C. P., Gretzel, U., Yuan, Y., \& Lamsfus, C. (2014). Smart tourism ecosystem workshop. Paper presented at ENTER 2014.

Koo, C. M., Kim, J. H., \& Chung N. H. (2014). Theorization and utilization of smart tourism ecosystems. Information Systems Review, 16(3), 69-87.

Koo, C., Shin, S., Gretzel, U., Hunter, W. C., \& Chung, N. (2016). Conceptualization of smart tourism destination competitiveness. Asia Pacific Journal of Information Systems, 26(4), 561-576.

Koo. C. M., Shin, S.H., Kim, K. H., Kim, C. W., \& Chung, N. H. (2013). Smart Tourism of the Korea: A case study. Paper presented at PACIS 2013.

Lee, S., \& Jing, D. (2015). Use Intentions of Mobile Tour Apps through Expansion of the Technology Acceptance Model. Journal of Distribution Science, 13(10), 135-142.

Li, Q. Z., \& Lee, J. H. (2017). The influential relations on sharing economy and consumer traits. International Jornal of Industrial Distribution \& Business, 8(6), 75-86.

Li, Y., Hu, C., Huang, C., \& Duan, L. (2017). The concept of smart tourism in the context of tourism information services. Tourism Management, 58, 293-300.

Lopes, R. O., Malik, O. A., Kumpoh, A. A. Z. A., Keasberry, C., Hong, O. W., Lee, S. C. W., \& Liu, Y. (2019, September). Exploring Digital Architectural Heritage in Brunei
Darussalam: Towards Heritage Safeguarding, Smart Tourism, and Interactive Education. Paper presented at the 2019 IEEE Fifth International Conference on Multimedia Big Data (BigMM) (pp. 383-390). IEEE.

Maehara, C., Yatsugi, K., Kim, D. W., \& Ushiama, T. (2012). An Exhibit Recommendation System Based on Semantic Networks for Museum. Studies in Computational Intelligence, 376, 131-141.

Mak, A. H. N., Lumbers, M., Eves, A., \& Chang, R. C. Y. (2013). An application of the repertory grid method and generalised Procrustes analysis to investigate the motivational factors of tourist food consumption. International Journal of Hospitality Management, 35, 327-338.

Pradhan, M. K., Oh, J., \& Lee, H. (2018). Understanding travelers' behavior for sustainable smart tourism: A technology readiness perspective. Sustainability, 10(11), 4259.

Purnomo, S., Rahayu, E. S., Riani, A. L., Suminah, S., \& Udin, U. (2020). Empowerment Model for Sustainable Tourism Village in an Emerging Country. The Journal of Asian Finance, Economics and Business, 7(2), 261-270.

Scott, N., Baggio, R., \& Cooper, C. (2008). Network analysis and tourism: From theory to practice. Bristol, United Kingdom: Channel View Publications.

Tan, G. W. H., Lee, V. H., Lin, B., \& Ooi, K. B. (2017). Mobile applications in tourism: the future of the tourism industry. Industrial Management \& Data Systems, 117(3), 560-581.

Yoo, C., Kwon, S., Na, H., \& Chang, B. (2017). Factors affecting the adoption of gamified smart tourism applications: An integrative approach. Sustainability, 9(12), 2162.

Wang, D., Park, S. W., \& Fesenmaier, D. R. (2012). The role of smartphones in mediating the touristic experience. Journal of Travel Research, 51(4), 371-387. 